\title{
Effects of Dipeptidyl Peptidase-4 Inhibitors on Carotid Intima-Media Thickness in Type 2 Diabetes Patients: A Systematic Review and Meta-Analysis
}

\author{
Xin $\mathrm{M}^{1 *}$, Zhou DY² and Yang Zhou $\mathrm{D}^{1}$ \\ ${ }^{1}$ Department of Endocrinology, China \\ ${ }^{2}$ Department of Science and Technology, China \\ ${ }^{*}$ Corresponding author: Xin M, Department of Endocrinology, China
}

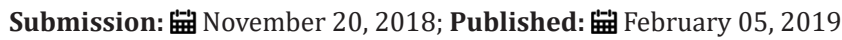

\begin{abstract}
Background: Recent studies suggested that dipeptidyl peptidase-4 (DPP-4) inhibitors benefit to atherosclerosis-related cardiovascular diseases, but evidence was inconclusive. We aimed to determine the effects of dipeptidyl peptidase-4 inhibitors on Carotid Intima-Media Thickness in type 2 diabetes patients.

Methods: A literature search was conducted via electronic databases. The inclusion criteria were randomized controlled trials (RCTs) comparing DPP-4 inhibitors to placebo or anti-hyperglycaemic agent, study duration of no less than 12 weeks performed in type 2 diabetes patients. The primary outcome was the Intima-Media Thickness of Carotid. Random-effects model were applied to data synthesis.

Results: Five trials enrolling 762 and 761 patients for DPP-4 inhibitors and placebo or anti hyperglycaemic agent were included. The primary outcome of this meta-analysis was mean intima media thickness common carotid artery (mean-IMT-CCA) and left maximum intima media thickness of the common carotid artery (max-left-IMT-CCA). There were no obvious differences in mean-IMT-CCA (SMD: - $0.2466,95 \%$ CI [-0.6052, 0.1120], P=0.1777) over 12 months. And that's the same for 24 months (SMD: -0.5249 , 95\%CI [-1.1492, 0.0994], $\mathrm{P}=0.0994)$. There was no significant difference between DPP-4 Inhibitors and placebo or anti hyperglycemic agent in max-left-IMT-CCA, (SMD:0.2217, 95\%CI [-0.2602, 0.7035], P=0.3673). And remained same over 24 months (SMD:0.1064, 95\%CI [-0.3498, 0.5627], $\mathrm{P}=0.6475$ ).
\end{abstract}

Conclusion: There is no significant decrease on Carotid Intima-Media Thickness after DPP-4 inhibitors treatment over 12 and 24 weeks.

Keywords: Dipeptidyl peptidase-4 inhibitors; Carotid intima media thickness; Meta-analysis; Chronic treatment

\section{Introduction}

Dipeptidyl peptidase 4 (DPP-4) inhibitors are new anti-diabetic drugs; such as alogliptin; linagliptin; saxagliptin; sitagliptin and vildagliptin; can reduce blood glucose mainly by inhibit glucagon release through the enhancement of glucagon-like peptide-1 (GLP-1) and gastric inhibitory peptide (GIP) [1]. DPP-4 inhibitors are also proposed have beneficial Cardioprotective effects [2]. Cardiovascular disease (CVD) is a major cause of morbidity and mortality in patients with type 2 diabetes mellitus (T2DM) $[3,4]$. Some research shows that chronic treatment with DDP-4 inhibitors may have cardioprotective effects in diabetes patients presenting with acute coronary syndrome [5]. Some research has a different view; they find DPP-4 inhibitors have not been shown to be associated with an increased risk of cardiovascular events $[6,7]$. The conclusion is uncertain. Carotid intima-media thickness (IMT) is a marker for atherosclerosis [8]. Evidence from preclinical studies suggests that DPP-4 inhibitors could have beneficial effects on atherosclerosis in both GLP-1-dependentand -independent manners [9]. The aim of this study was to determine the effect of DPP-4 inhibitors treatment on Carotid Intima-Media Thickness in diabetic patients; by means of a systematic review and a metaanalysis.

\section{Methods}

\section{Outcome and search strategy}

The primary outcome of this meta-analysis was mean intima media thickness common carotid artery (mean-IMT-CCA) and left maximum intima media thickness of the common carotid artery(max-left-IMT-CCA) .An electronic literature search of PubMed; the Cochrane Library without language restriction until Dec 2017; using keywords including alogliptin; linagliptin; saxagliptin; sitagliptin; vildagliptin; dipeptidyl peptidase 4 inhibitors and DPP-4 inhibitors.

\section{Study selection criteria}

The literature search; selection of studies; and extraction of data was done independently by 2 reviewers (Kuijun Zhan; Kaiyuan LIU). Disagreements were resolved by consensus. Included studies had to meet the following criteria: 
A. All studies involved patients with type two diabetes mellitus.

B. Two groups diabetic patients where one group was treated with DPP-4 inhibitors and the other with placebo or other treatments.

C. All studies contain CIMT outcomes.

D. Clinical; double-blind randomized controlled trial; The placebo group and the DPP-4 inhibitors group that were compared should have the same kind of treatment and care in all other ways (for example; education regarding diet and lifestyle changes).

\section{Data extraction}

Recorded data included characteristics of the studies; demographic data; and Carotid intima-media thickness changes in patients allocated to DPP-4 inhibitors or conventional therapy.

\section{Statistical methods}

Tabulated data on study characteristics were prepared. All values were expressed as standardized mean differences (SMDs) with 95\% credible intervals (CIs). Homogeneity among studies was tested by means of Cochran's $Q$ test and calculation of the variation across studies attributable to heterogeneity rather than chance (I2). When substantial heterogeneity was demonstrated ( $p$ value $<0.1$ or a I 2 value $>50 \%$ ); a random-effects model was used; otherwise a fixed-effect model was used. Sensitivity analyses were performed with pooled estimate by omitting one study at a time. All analyses were performed in R (version 3.4.2), using 'meta' package (version 4.8-4).

\section{Result}

\section{Flow and identification of studies}

A total of 184 citations were identified through our extensive search. 167 studies were excluded because of exclusion were irrelevant or lacking original data). Thirteen of the 17 studies were excluded for irrelevant or not fulfilling the inclusion criteria. Four studies fulfilled the inclusion criteria and were included in the final analysis [10-14]. A total of 1523 patients were included in the five studies; the demographic and baseline biochemical parameters of the included studies are shown in Table 1. Among those articles included; two of them came from Japan; and all the four trials are in English literature (Table 1) \& (Figure 1).

Table 1: Baseline clinical characteristics of patient.

\begin{tabular}{|c|c|c|c|c|c|c|c|c|c|c|c|c|c|}
\hline & \multirow[b]{2}{*}{ Experiment } & \multirow[b]{2}{*}{ Country } & \multirow{2}{*}{$\begin{array}{c}\text { Follow- } \\
\text { up(months) }\end{array}$} & \multicolumn{5}{|c|}{ Intervention Group } & \multicolumn{5}{|c|}{ Control Group } \\
\hline & & & & $\mathbf{N}$ & Male & $\begin{array}{c}\text { Age } \\
\text { (years) }\end{array}$ & $\begin{array}{c}\text { HbA1c } \\
\text { (圆) }\end{array}$ & $\begin{array}{c}\text { BMI (kg/ } \\
\left.\text { m }^{2}\right)\end{array}$ & $\mathbf{N}$ & Male & Age & $\begin{array}{c}\text { HbA1c } \\
\text { (圆) }\end{array}$ & $\begin{array}{c}\text { BMI (kg/ } \\
\left.\text { m }^{2}\right)\end{array}$ \\
\hline $\begin{array}{c}\text { Ishikawa } \\
2014\end{array}$ & $\begin{array}{l}\text { sitagliptin } \\
100 \mathrm{mg} / \text { day }\end{array}$ & Japan & 12 & 37 & 32 & $73.7 \pm 7.3$ & - & $25.3 \pm 3.9$ & 39 & 33 & $69.0 \pm 8.0$ & - & $23.8 \pm 3.1$ \\
\hline $\begin{array}{c}\text { Mita } \\
\text { (Alogliptin) } \\
2016\end{array}$ & $\begin{array}{l}\text { Alogliptin } \\
25 \mathrm{mg} / \text { day }\end{array}$ & Japan & 12,24 & 172 & 101 & $64.4 \pm 9.8$ & $7.3 \pm 0.8$ & $24.6 \pm 4.3$ & 169 & 98 & $64.8 \pm 9.1$ & $24.9 \pm 3.7$ & $7.2 \pm 0.8$ \\
\hline $\begin{array}{c}\text { Mita } \\
\text { (Sitagliptin) } \\
2016\end{array}$ & $\begin{array}{l}\text { sitagliptin } \\
25 \text { or } 50 \\
\text { mg/day; } 50 \\
\text { or } 100 \mathrm{mg} / \\
\text { day }\end{array}$ & Japan & 12,24 & 142 & 83 & $63.8 \pm 9.7$ & $8.1 \pm 1.1$ & $25.0 \pm 4.3$ & 140 & 82 & $63.6 \pm 1.0$ & $8.0 \pm 1.0$ & $25.0 \pm 3.8$ \\
\hline $\begin{array}{l}\text { Oyama } \\
2016\end{array}$ & sitagliptin & Japan & 12,24 & 222 & 146 & $69.2 \pm 9.3$ & $\begin{array}{c}6.96 \pm \\
0.64\end{array}$ & $25.3 \pm 4.1$ & 220 & 151 & $69.5 \pm 9.2$ & $\begin{array}{c}6.96 \pm \\
0.55\end{array}$ & $24.9 \pm 4.0$ \\
\hline Mita 2017 & sitagliptin & Japan & 24 & 137 & 82 & $63.6 \pm 10.0$ & $8.0 \pm 1.0$ & $25.1 \pm 3.4$ & 137 & 83 & $63.2 \pm 9.6$ & $8.3 \pm 1.1$ & $25.2 \pm 4.4$ \\
\hline
\end{tabular}

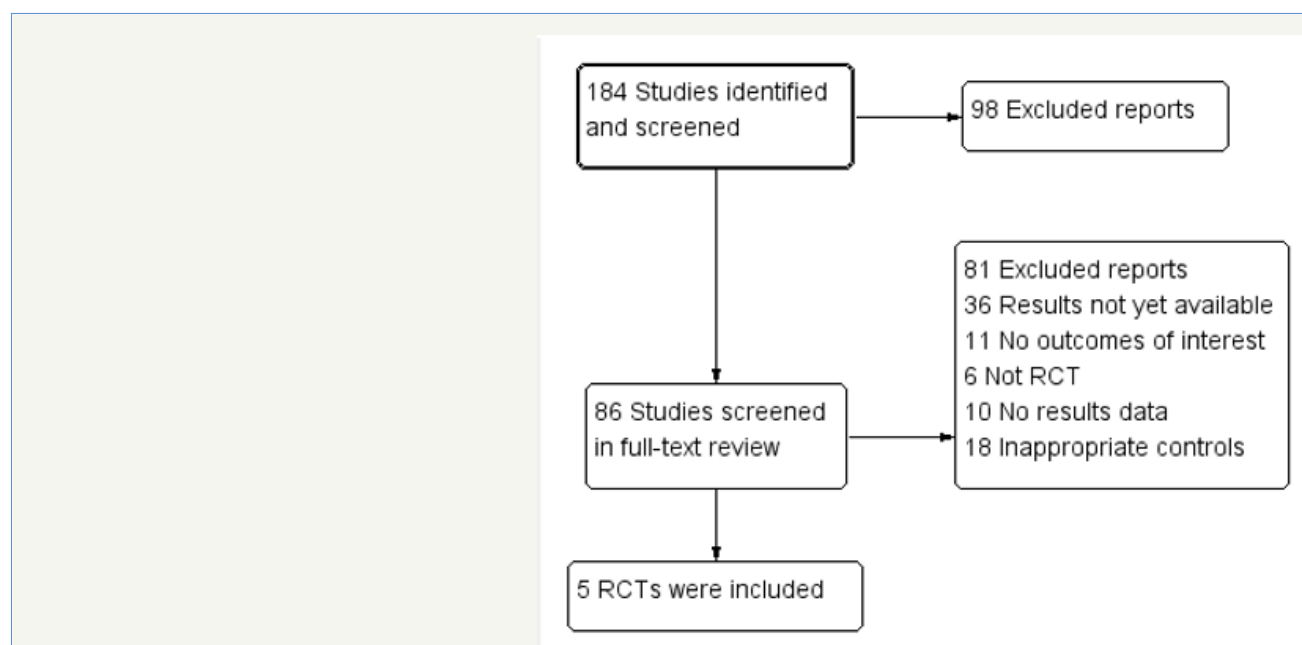

Figure 1: Flow diagram of literature search and study selection. 


\section{Risk of bias assessment}

The risk of bias of included trials was assessed according to the recommendations of the Cochrane Handbook of Systematic Reviews of Interventions (Figure 2).

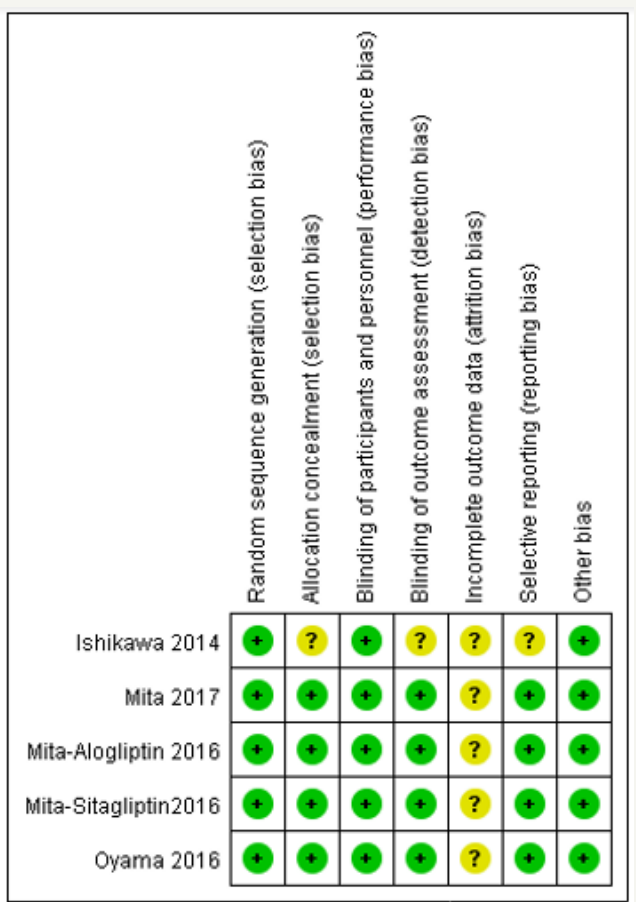

Figure 2: Literature quality evaluation.

\section{Effect of DPP-4 inhibitors on IMT}

We performed separate meta-analyses for each outcome (meanIMT-CCA and max-left-IMT-CCA) on 12 months and 24months.For large heterogeneity; we are using random-effects model. MeanIMT-CCA. As shown in Figure 3 \& 4; Over 12 months; there was no significant difference between DPP-4 Inhibitors and placebo or antihyperglycaemic agent in mean-IMT-CCA; (SMD: -0.2466;95\%CI: [-0.6052; 0.1120]; $\mathrm{P}=0.1777$ ). And remained over 24 months (SMD: $-0.5249 ; 95 \%$ CI: [-1.1492; 0.0994]; $\mathrm{P}=0.0994$ ) (Figure 3 \& 4).

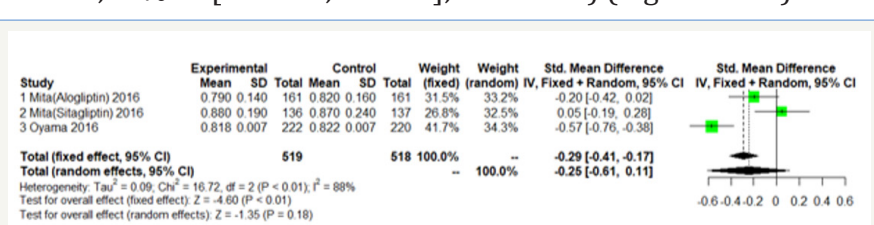

Figure 3: Mean-IMT-CCA on 12 months.

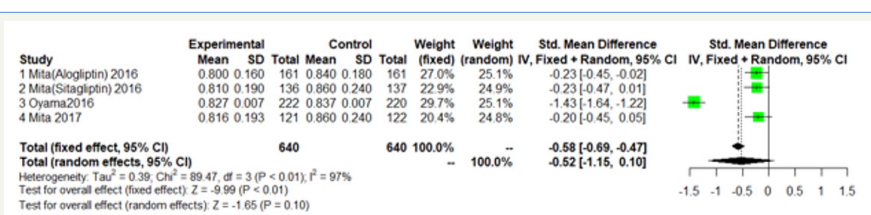

Figure 4: Mean-IMT-CCA on 24 months.

\section{Max-left-IMT-CCA.}

As shown in Figure 5 \& 6; Over 12 months; there was no significant difference between DPP-4 Inhibitors and placebo or anti hyperglycemic agent in max-left-IMT-CCA; (SMD:0.2217;95\%CI: [-0.2602; 0.7035]; $\mathrm{P}=0.3673)$. And remained over 24 months (SMD:0.1064;95\%CI: [-0.3498; 0.5627]; $\mathrm{P}=0.6475$ ) (Figure 5 \& 6).

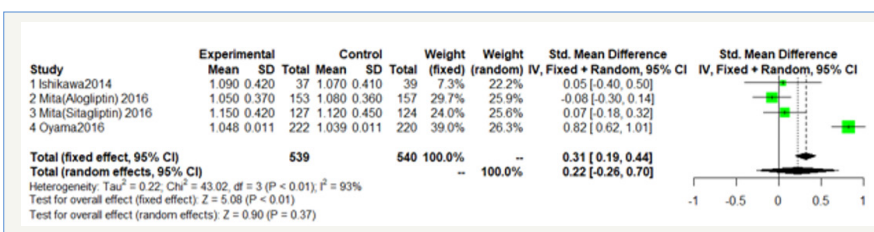

Figure 5: Max-left-IMT-CCA on 12 months.

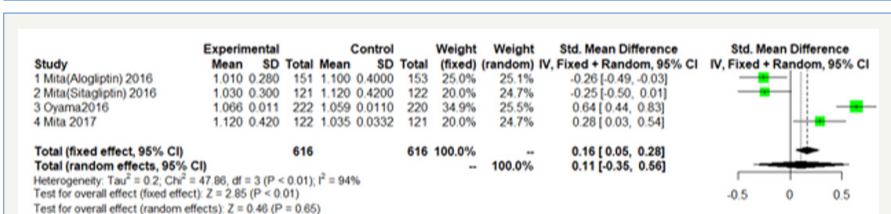

Figure 6: Max-left-IMT-CCA on 24 months.

\section{Sensitivity analyses}

Sensitivity analyses were shown in Figure $7 \& 8$. One of the literature has a great influence on the results. Excluded the literature; heterogeneity reduced; the DPP4 group has lower meanCCA-IMT (Fixed effect model; SMD: -0.2234; 95\%CI [-0.3593; $-0.0876] ; \mathrm{P}=0.0013)$. But no significant difference in max-left-CCAIMT;(SMD:0.0761; 95\%CI [-0.4209; 0.2686]; $\mathrm{P}=0.6651)$. But the three literatures come from the same study and may be biased (Figure 7 \& 8).

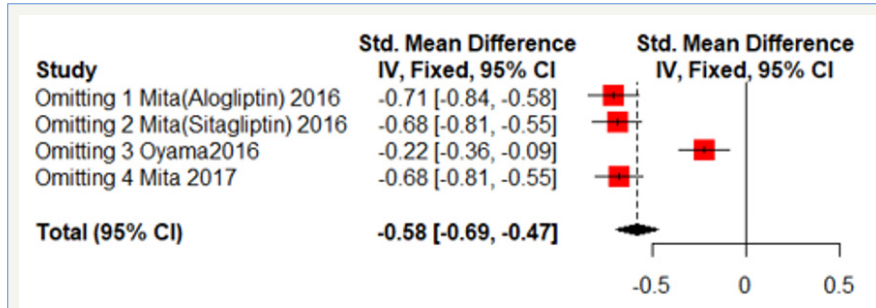

Figure 7: Mean-IMT-CCA on 24 months.

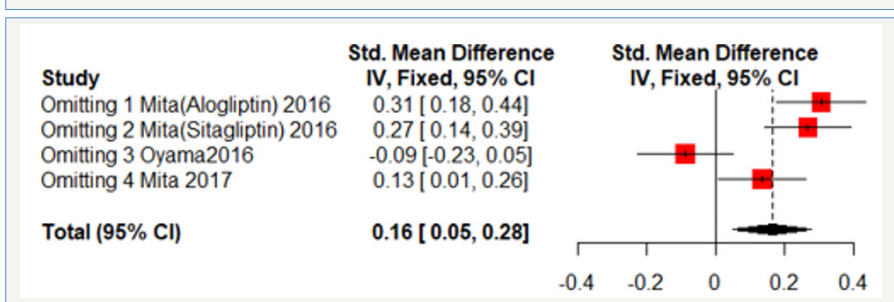

Figure 8: Max-left-IMT-CCA on 24 months.

\section{Discussion}

Five trials enrolling 762 and 761 patients for DPP-4 inhibitors and comparators were included. DPP-4 inhibitors; compared with placebo or other treatments; were associated with a reduced risk. DPP-4 inhibitors treatment did not suggest a significant Carotid Intima-Media Thickness reduction compared with placebo. Dipeptidyl peptidase-4 (DPP-4) inhibitors are an antihyperglycemic drugs that block degradation of incretin hormones. By enhancing and prolonging incretin effects; DPP-4 inhibitors stimulate glucosedependent insulin secretion and also reduce glucagon secretion. This results in improved glycemic control; as reflected by decreases 
in glycated hemoglobin (HbA1c); fasting plasma glucose; and postprandial plasma glucose. Dipeptidyl peptidase-4 inhibitors also have the potential to improve beta-cell function [15]. Sitagliptin produces approximately 2-3fold increases in active glucagonlike peptide-1 (GLP-1) and glucose-dependent insulinotropic polypeptide (GIP) levels [16].

Glucagon-like peptide-1 (GLP-1) receptors are abundantly expressed in vascular cells such as endothelial cells; monocyte/ macrophages and smooth muscle cells. The anti-inflammatory and vasodilatory properties of glucagon-like peptide- 1 signaling on endothelial cells; its anti-inflammatory effect on macrophages and anti-proliferative effects on smooth muscle cells may halt atherosclerosis [17]. Furthermore; some studies indicate that sitagliptin can reduce the area of the atherosclerotic lesion; possibly by regulating the AMPK and MAPK pathways and then reducing leukocyte-endothelial cell interaction and inflammation reactions [18]. Atherosclerosis is the main pathological feature of diabetic cardiovascular complications. Thus; the beneficial effect of DPP-4 inhibitors on atherosclerosis; though which are small; could contribute to the reduction of cardiovascular risk.

A Further study are needed to identify the time DPP-4 inhibitors to reduce Carotid Intima-Media Thickness. Among those articles included; two of them came from Japan; and all the four trials are in English literature. Thus; some biases may exist. One of the literature has a great influence on the results. Excluded the literature; heterogeneity reduced; the DPP-4 inhibitors group has lower mean-CCA-IMT(;Fixed effect model; SMD:-0.2234; 95\%CI $[-0.3593 ;-0.0876] ; \mathrm{P}=0.0013)$. In the view of the results of this meta-analysis; a more careful assessment of Carotid Intima-Media Thickness and the DPP-4 inhibitors treatment time is suggested; as well as prospective studies are needing to be performed.

\section{Conclusion}

There is no significant difference of adverse reactions in DPP-4 inhibitors and conventional therapy group.

\section{References}

1. Mulvihill EE, Drucker DJ (2014) Pharmacology, physiology, and mechanisms of action of dipeptidyl peptidase-4 inhibitors. Endocr Rev 35(6): 992-1019.

2. Koska J, Sands M, Burciu C, Reaven P (2015) Cardiovascular effects of dipetidyl peptidase-4 inhibitors in patients with type 2 diabetes. J Diab Vasc Dis Res 12(3): 154-163.

3. Haffner SM, Lehto S, Rönnemaa T, Pyörälä K, Laakso M (1998) Mortality from coronary heart disease in subjects with type 2 diabetes and in nondiabetic subjects with and without prior myocardial infarction. $\mathrm{N}$ Engl J Med 339(4): 229-234.

4. Sarwar N, Gao P, Seshasai SR, Gobin R, Kaptoge S, et al. (2010) Diabetes mellitus, fasting blood glucose concentration, and risk of vascular disease: A collaborative meta-analysis of 102 prospective studies. Lancet 375(9733): 2215-2222.

5. Gevrielov YN, Matetzky S, Gavish D, Goldenberg I, Gottlieb S, et al. (2013) Sitagliptin pretreatment in diabetes patients presenting with acute; coronary syndrome: Results from the acute coronary syndrome Israeli survey (ACSIS). Cardiovasc Diabetol 12(1): 53.

6. Williams HD, Engel SS, Round E, Johnson J, Golm GT, et al (2010) Safety and tolerability of sitagliptin in clinical studies: A pooled analysis of data from 10,246 patients with type 2 diabetes. BMC Endocr Disord 10: 7.

7. Engel SS, Golm GT, Shapiro D, Davies MJ, Kaufman KD, et al. (2013) Cardiovascular safety of sitagliptin in patients with type 2 diabetes mellitus: A pooled analysis. Cardiovascular Diabetology 12: 3.

8. Bots ML, Mulder PG, Hofman A, Van Es GA, Grobbee DE (1994) Reproducibility of carotid vessel wall thickness measurements. The Rotterdam Study. J Clin Epidemiol 47: 921-930.

9. Matsubara J, Sugiyama S, Sugamura K, Nakamura T, Fujiwara Y, et al. (2012) A dipeptidyl peptidase-4 inhibitor, des-fluoro-sitagliptin, improves endothelial function and reduces atherosclerotic lesion formation in apolipoprotein E-deficient mice. J Am Coll Cardiol 59(3): 265-276.

10. Mita T, Katakami N, Yoshii H, Onuma T, Kaneto H, et al. (2016) Alogliptin, a dipeptidyl peptidase-4 inhibitor, prevents the progression of carotid atherosclerosis in patients with type 2 diabetes: The study of preventive effects of alogliptin on diabetic atherosclerosis (SPEAD-A). Diabetes Care 39(1): 139-148.

11. Ishikawa S, Shimano M, Watarai M, Koyasu M, Uchikawa T, et al. (2014) Impact of sitagliptin on carotid intima-media thickness in patients with coronary artery disease and impaired glucose tolerance or mild diabetes mellitus. Am J Cardiol 114(3): 384-388.

12. Jun IO, Toyoaki M, Masafumi K, shizu T, Sato Y, et al. (2016) The effect of sitagliptin on carotid artery atherosclerosis in type 2 diabetes: The prologue randomized controlled trial. Plos Med 13(6): e1002051.

13. Mita T, Katakami N, Shiraiwa T, Onuma T, Kuribayashi N, et al. (2016) Sitagliptin attenuates the progression of carotid intima-media thickening in insulin-treated patients with type 2 diabetes: The sitagliptin preventive study of intima-media thickness evaluation (SPIKE): A randomized controlled trial. Diabetes Care 39(3): 455-464.

14. Mita T, Katakami N, Shiraiwa T, Yoshii H, Gosho M (2017) Dosedependent effect of sitagliptin on carotid atherosclerosis in patients with type 2 diabetes mellitus receiving insulin treatment: A post hoc analysis. Diabetes Ther 8(5): 1135-1146.

15. Hollander PA, Kushner P (2010) Type 2 diabetes comorbidities and treatment challenges: Rationale for DPP-4 inhibitors. Postgrad Med 122(3): 71-80.

16. Bo A (2010) Use of DPP-4 inhibitors in type 2 diabetes: Focus on sitagliptin. Diabetes Metab Syndr Obes 3: 31-41.

17. Mita T, Watada H (2012) Glucagon like Peptide-1 and atherosclerosis. Cardiovasc Hematol Agents Med Chem 10(4): 309-318.

18.Zeng Y, Li C, Guan M, Zheng Z, Li J, et al. (2014) The DPP-4 inhibitor sitagliptin attenuates the progress of atherosclerosis in apolipoproteinE-knockout mice via AMPK- and MAPK-dependent mechanisms. Cardiovascular Diabetology 13: 32. 
Creative Commons Attribution 4.0 International License

For possible submissions Click Here
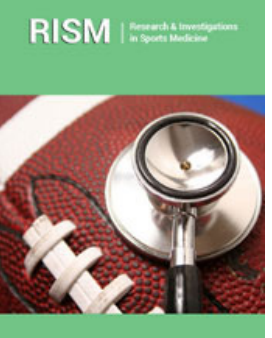

Research \& Investigations in Sports Medicine

\section{Benefits of Publishing with us}

- High-level peer review and editorial services

- Freely accessible online immediately upon publication

- Authors retain the copyright to their work

- Licensing it under a Creative Commons license

- Visibility through different online platforms 